\title{
Serum Adiponectin Level in Patients with Psoriasis and its Correlation with the Clinical Severity \\ Mahmoud Yousry Abdel-Mawla ${ }^{1}$, Naglaa Ali Khalifa ${ }^{2}$, Aisha Hamza Gamil*1, Mohamed Mahmoud Nasr ${ }^{1}$ \\ Departments of ${ }^{1}$ Dermatology, Venereology and Andrology and ${ }^{2}$ Clinical Pathology, Faculty of Medicine, Zagazig University, Egypt \\ *Corresponding Author: Aisha Hamza Gamil, Mobile: (+20)1004072373, E-mail: aishahamzawy2014@ gmail.com
}

\begin{abstract}
Background: Psoriasis is a common chronic immune mediated papulosquamous disease that affects 2-3\% of the population. The exact cause of psoriasis is still unclear, but it is considered a disease of dysregulated inflammation which is driven and maintained by interaction among multiple components of immune system in genetically predisposed individuals. Adipose tissue is an active endocrine organ contributing to the regulation of multiple metabolic pathways via self-produced bioactive products called adipokine. Adiponectin of adipose origin has the highest circulating concentration among the known adipokines. Adiponectin regulates skin inflammation especially IL-17-related psoriasiform dermatitis. Objective: This study was aimed to estimate the serum level of Adiponectin and detect its correlation with activity of psoriatic patients.

Patients and Methods: This case control study included a total of 50 patients with psoriasis and 50 healthy individuals, attending at Outpatient Clinic, Department of Dermatology, Venereology and Andrology in collaboration with Department of Clinical Pathology, Faculty of Medicine, Zagazig University Hospitals. This study was conducted between November 2019 to November 2020. Psoriasis severity was classified according to psoriatic area and severity index (PASI) score. Serum level of adiponectin was determined by ELISA for both groups.

Results: The results revealed that control group had significantly higher level of adiponectin than psoriasis patients. There was a negative significant correlation between adiponectin and Psoriasis Area and Severity Index (PASI score) $\left(\mathrm{p}<0.001^{* *}\right)$. Sensitivity of adiponectin in diagnosis of psoriasis was $94 \%$, specificity was $90 \%$ and accuracy was 92\%. Conclusion: Adiponectin measurement in serum of patients with psoriasis provides a tool for monitoring disease activity.
\end{abstract}

Keywords: Psoriasis, Adiponectin, PASI, Markers, Adipokines

\section{INTRODUCTION}

Psoriasis is a common chronic inflammatory skin condition. Crosstalk between epidermal keratinocytes, dermal vascular cells, and immunocytes such as antigen presentation cells (APCs) and T cells causes the distinctive epidermal and vascular hyperplasia seen in lesional psoriatic skin ${ }^{(\mathbf{1})}$. The cause of psoriasis is unclear; however, it is thought to be multifaceted, with many essential components such as genetic vulnerability, environmental triggers, skin barrier disturbance, and immunological dysfunction ${ }^{(2)}$.

There have been strong claims in years supporting the systemic involvement of adipose tissue in the pathogenesis of psoriasis. The physiologic condition of systemic white adipose tissue (WAT), particularly the intensity and variety of released adipokines, has been linked to the pathophysiology and inflammatory character of psoriasis, resulting in imbalanced production of pro- and anti-inflammatory signalling proteins. This research backs up the theory that WAT has a role in the development of several skin diseases, including psoriasis ${ }^{(3)}$.

Adiponectin (GBP28, adipoQ, ACRP30) is a collagen-like plasma protein with a molecular weight of $28 \mathrm{kDa}$ in human. It has a plasma concentration ranging from 5 to $30 \mu \mathrm{g} / \mathrm{mL}$. This protein of adipose origin has the highest circulating concentration among the known adipokines ${ }^{(4)}$.

A small amount of a processed globular form of adiponectin was reported to be present in human plasma (5). Plasma concentrations reveal a sexual dimorphism, with females having higher levels than males. Levels of adiponectin are reduced in diabetics compared to non-diabetics; also weight reduction significantly increases circulating levels of adiponectin (6). It is also varied according to age as it has been decreased in males at the puberty ${ }^{(7)}$. Adiponectin has anti-inflammatory effects by inhibiting the activity and secretion of proinflammatory cytokines, including IL2 , IL-6, TNF- $\alpha$ and IFN- $\gamma$. It enhances the production of anti-inflammatory cytokines, including IL-10. Upregulation of anti-inflammatory cytokines can help restore the imbalance between Th1/Th17 and Th2 responses that affect patients with psoriasis ${ }^{(8)}$. In patients with psoriasis, circulating adiponectin level has been shown to be decreased as compared to healthy controls ${ }^{(9)}$. A negative correlation between adiponectin and extent of the skin disease evaluated by psoriasis severity index (PASI) or pro-inflammatory cytokines, such as IL-6 and TNF $\alpha$ was found in these studies ${ }^{(\mathbf{1 0})}$.

From these studies, adiponectin plays a crucial role to regulate psoriasis inflammation by directly suppressing IL-17 production from T cells. 
The aims of the current work were to assess serum level of adiponectin in patients with psoriasis and to detect its correlation with its activity and severity.

\section{PATIENTS AND METHODS}

This case control study included a total of 50 patients with psoriasis and 50 healthy individuals, attending at Outpatient Clinic, Department of Dermatology, Venereology and Andrology in collaboration with Department of Clinical Pathology, Faculty of Medicine, Zagazig University Hospitals. This study was conducted between November 2019 to November 2020.

The included participated subjects were of both sexes and different ages. They were divided into Group (I): 50 psoriatic patients, 33 males and 17 females and their age ranged from 18 to 65 years. Psoriasis severity was classified according to psoriatic area and severity index (PASI) score. Group (II): 50 healthy individuals, 24 male and 26 females and their age ranged from 18 to 65 years. Demographic characteristics of the patients at the beginning of the study are shown in Table (1). Inclusion criteria included patients of both sexes with psoriasis vulgaris. Exclusion criteria included patients who had received any systemic treatments or ultraviolet therapy for psoriasis in the prior 6 months, and the presence of any systemic disease or those younger than 18 years of age.

All patient and control groups were subjected to the following: Detailed history taking which included personal history, history of associated other dermatological or systemic diseases, history of drug intake and family history. General examination of body systems was performed to discover associated medical conditions including pulse, blood pressure and joint examination. Also, body mass index (BMI) was evaluated for both groups ${ }^{(11)}$.

Detailed dermatological examination: Complete dermatological examination was done involving skin, hair, mucous membranes, and nails.

The severity of Psoriasis is assessed by the Psoriasis Area and Severity Index (PASI score) as follow: The body was divided into four sections (head $(\mathrm{H})(10 \%$ of a person's skin); arms (A) (20\%); trunk (T) (30\%); legs (L) $(40 \%))$. Each of these areas was scored separately, and then the four scores are combined into the final PASI. For each section, the percent of area of skin involved, was estimated and then transformed into a grade from 0 to 6 as previously described. Within each area, the severity was estimated by three clinical signs: erythema (redness) E, induration (thickness) I and desquamation (scaling) D. Severity parameters were measured on a scale of 0 to 4 , from none to very severe. Finally, the sum of all three severity parameters was then calculated for each section of skin, multiplied by the area score for that area and multiplied by weight of respective section $(0.1$ for head, 0.2 for arms, 0.3 for body and 0.4 for legs $)^{(12,13)}$.

Laboratory investigation: Serum level of adiponectin was measured by ELISA for both groups according to manufacturer instructions ${ }^{(14,15)}$.

\section{Ethical Considerations:}

This work has been carried out in accordance with The Code of Ethics of the World Medical Association (Declaration of Helsinki) for studies involving humans. Written informed consents were obtained from the study participants. Approval by IRB research committee of Zagazig Faculty of Medicine was also included.

\section{Statistical analysis}

After the data collection, the data was analyzed by statistical package of SPSS-19 and the following tests were used: Chi-square $\left(\mathrm{X}^{2}\right)$, Student t-test, Spearman's correlation coefficient (r), and One way

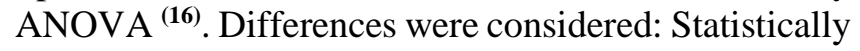
significant $(\mathrm{S})$ when $(\mathrm{P}<0.05)$ and Non-significant (NS) when (P> 0.05). A receiver operating characteristic (ROC) curve analysis was conducted to evaluate the performance of Adiponectin assay for the prediction of active psoriasis disease. The sensitivity (true positive rate), specificity (true negative rate), is estimated and confidence interval (CI) of $95 \%$, were obtained for each study and subsequently combined. The statistical analysis was based on the intention-totreat population.

Data was represented as mean $\pm \mathrm{SD}$, range, numbers or percentages.

\section{RESULTS}

There was not statistically significance difference between the two studied groups regarding age, sex distribution or obesity as can be seen in table (1). The duration of psoriasis among the studied psoriasis group ranged from 1 to 20 years with mean 6.16 years. Regarding family history only $4 \%$ had positive family history of psoriasis. Table (2) shows that the PASI score of psoriasis among the studied psoriasis group ranged from 0.8 to 23.8 with mean 10.62 . All cases had erythema, induration and scale. Regarding MS (metabolic syndromes) (Diabetes, Hypertension) it was founded in 38\% of the cases. The severity of psoriasis according to PASI score was as follow $48 \%$ of patients was mild, $40 \%$ was moderate and $12 \%$ was severe.

There was a statistically significant decrease in adiponectin in Group I compared to Group II as can be seen in Table (3) with a mean 0.53 , and 3.39 respectively. Moreover, there was a negative significant correlation between adiponectin and PASI score among psoriasis patients as illustrated in figure (1). Table (4) shows that there was no statistical significant relation between sex, obesity, family history, MS and adiponectin level among psoriasis group. Sensitivity of adiponectin in diagnosis of 
psoriasis at cut off $<1.12 \mathrm{ng} / \mathrm{ml}$ was $94 \%$, specificity was $90 \%$ and accuracy was $92 \%$ as can be detected in

figure (2).

Table (1): Demographic data of the studied groups.

\begin{tabular}{|c|c|c|c|c|c|c|c|}
\hline \multicolumn{2}{|c|}{ Variable } & \multirow{2}{*}{\multicolumn{2}{|c|}{$\begin{array}{c}\begin{array}{c}\text { Group I } \\
\text { (Psoriasis) } \\
(\boldsymbol{n}=\mathbf{5 0})\end{array} \\
39.74 \pm 13.09 \\
19-64\end{array}$}} & \multirow{2}{*}{\multicolumn{2}{|c|}{$\begin{array}{c}\begin{array}{c}\text { Group II } \\
(\text { Control) } \\
(\mathbf{n = 5 0})\end{array} \\
35.94 \pm 7.96 \\
20-50\end{array}$}} & \multirow{3}{*}{$\begin{array}{c}1.75 \\
\chi^{2}\end{array}$} & \multirow{3}{*}{$\begin{array}{c}\mathbf{P} \\
0.08 \\
\mathrm{NS} \\
\mathbf{P} \\
\end{array}$} \\
\hline Age: (years) & $\begin{array}{c}\text { Mean } \pm \text { Sd } \\
\text { Range }\end{array}$ & & & & & & \\
\hline \multicolumn{2}{|c|}{ Variable } & No & $\%$ & No & $\%$ & & \\
\hline Sex: & $\begin{array}{c}\text { Female } \\
\text { Male }\end{array}$ & $\begin{array}{l}17 \\
33\end{array}$ & $\begin{array}{l}34 \\
66\end{array}$ & $\begin{array}{l}26 \\
24\end{array}$ & $\begin{array}{l}52 \\
48\end{array}$ & 3.31 & $\begin{array}{c}0.07 \\
\text { NS }\end{array}$ \\
\hline $\begin{array}{l}\text { Obesity: } \\
(\mathrm{BMI})\left(\mathrm{kg} / \mathrm{m}^{2}\right)\end{array}$ & $\begin{array}{l}\text { No } \\
\text { Yes }\end{array}$ & $\begin{array}{l}32 \\
18 \\
\end{array}$ & $\begin{array}{l}64 \\
36 \\
\end{array}$ & $\begin{array}{l}29 \\
21 \\
\end{array}$ & $\begin{array}{l}58 \\
42 \\
\end{array}$ & 0.38 & $\begin{array}{c}0.54 \\
\mathrm{NS} \\
\end{array}$ \\
\hline
\end{tabular}

SD: Standard deviation t: Independent $t$ test $\chi 2$ :Chi square test. NS: Non significant (P>0.05) BMI: body mass index

Table (2): Clinical data of the psoriasis group.

\begin{tabular}{|c|c|c|c|}
\hline \multicolumn{2}{|c|}{ Variable } & \multirow{2}{*}{\multicolumn{2}{|c|}{$\begin{array}{c}\begin{array}{c}\text { Group I (Psoriasis) } \\
(\boldsymbol{n}=\mathbf{5 0})\end{array} \\
10.62 \pm 5.84 \\
10.8 \\
\end{array}$}} \\
\hline PASI: & $\begin{array}{l}\text { Mean } \pm \text { SD } \\
\text { Median }\end{array}$ & & \\
\hline \multicolumn{2}{|c|}{ Variable } & No & $\%$ \\
\hline Erthyma: & $\begin{array}{l}\text { No } \\
\text { Yes }\end{array}$ & $\begin{array}{c}0 \\
50\end{array}$ & $\begin{array}{c}0 \\
100\end{array}$ \\
\hline Induration: & $\begin{array}{l}\text { No } \\
\text { Yes }\end{array}$ & $\begin{array}{c}0 \\
50\end{array}$ & $\begin{array}{c}0 \\
100\end{array}$ \\
\hline Scale: & $\begin{array}{l}\text { No } \\
\text { Yes }\end{array}$ & $\begin{array}{c}0 \\
50\end{array}$ & $\begin{array}{c}0 \\
100\end{array}$ \\
\hline $\begin{array}{l}\text { MS: } \\
\text { Diabetes, Hypertension }\end{array}$ & $\begin{array}{l}\text { No } \\
\text { Yes }\end{array}$ & $\begin{array}{l}31 \\
19\end{array}$ & $\begin{array}{l}62 \\
38 \\
\end{array}$ \\
\hline Severity: & $\begin{array}{c}\text { Mild }(<\mathbf{1 0}) \\
\text { Moderate }(\mathbf{1 0}-<20) \\
\text { Sever }(\geq \mathbf{2 0}) \\
\end{array}$ & $\begin{array}{c}24 \\
20 \\
6 \\
\end{array}$ & $\begin{array}{l}48 \\
40 \\
12 \\
\end{array}$ \\
\hline
\end{tabular}

SD: Standard deviation

Table (3): Adiponectin level among the studied groups.

\begin{tabular}{||l|c|c|c|c|c|}
\hline \multicolumn{2}{|c|}{ Variables } & $\begin{array}{c}\text { Group I (Psoriasis) } \\
(\mathbf{n = 5 0 )}\end{array}$ & $\begin{array}{c}\text { Group II (Control) } \\
(\mathbf{n}=\mathbf{5 0})\end{array}$ & MW & P \\
\hline $\begin{array}{l}\text { Adiponectin: } \\
(\mathrm{ng} / \mathrm{ml})\end{array}$ & $\begin{array}{c}\text { Mean } \pm \text { Sd. } \\
\text { Median }\end{array}$ & $\begin{array}{c}0.53 \pm 0.13 \\
0.58\end{array}$ & $\begin{array}{c}3.39 \pm 0.57 \\
2.39\end{array}$ & $\mathbf{8 . 5 2}$ & $<\mathbf{0 . 0 0 1 * *}$ \\
\hline
\end{tabular}

SD: Standard deviation MW: Mann Whitney. *: Significant $(\mathrm{p}<0.05) * *$ : Highly significant $(\mathrm{P}<0.001)$

Table (4): Relation between Adiponectin \& some parameters of the psoriasis group:

\begin{tabular}{|c|c|c|c|c|c|c|c|}
\hline \multirow{2}{*}{\multicolumn{2}{|c|}{ Variable }} & \multirow{3}{*}{$\begin{array}{c}\text { No } \\
17 \\
33\end{array}$} & \multicolumn{3}{|c|}{$\begin{array}{l}\text { Adiponectin (ng/ml) }\end{array}$} & \multirow{3}{*}{$\begin{array}{c}\text { MW } \\
1.45\end{array}$} & \multirow{3}{*}{$\begin{array}{c}\mathbf{P} \\
0.15 \\
\mathrm{NS}\end{array}$} \\
\hline & & & Mean \pm SD & Median & Range & & \\
\hline Sex & $\begin{array}{c}\text { Female } \\
\text { Male }\end{array}$ & & $\begin{array}{l}0.42 \pm 0.19 \\
0.59 \pm 0.14\end{array}$ & $\begin{array}{l}0.56 \\
0.64\end{array}$ & $\begin{array}{c}0.009-0.76 \\
0.03-1.16\end{array}$ & & \\
\hline Obesity & $\begin{array}{l}\text { No } \\
\text { Yes }\end{array}$ & $\begin{array}{l}32 \\
18\end{array}$ & $\begin{array}{l}0.52 \pm 0.16 \\
0.55 \pm 0.10\end{array}$ & $\begin{array}{l}0.55 \\
0.65\end{array}$ & $\begin{array}{c}0.009-1.16 \\
0.03-0.91\end{array}$ & 0.77 & $\begin{array}{c}0.44 \\
\mathrm{NS}\end{array}$ \\
\hline $\begin{array}{l}\text { Family } \\
\text { history: }\end{array}$ & $\begin{array}{l}\text {-ve } \\
+ \text { ve }\end{array}$ & $\begin{array}{c}48 \\
2\end{array}$ & $\begin{array}{l}0.55 \pm 0.13 \\
0.07 \pm 0.03\end{array}$ & $\begin{array}{l}0.58 \\
0.07\end{array}$ & $\begin{array}{c}0.009-1.16 \\
0.06-0.08\end{array}$ & 1.96 & $\begin{array}{c}0.06 \\
\text { NS }\end{array}$ \\
\hline MS: & $\begin{array}{l}\text { No } \\
\text { Yes }\end{array}$ & $\begin{array}{l}31 \\
19 \\
\end{array}$ & $\begin{array}{l}0.47 \pm 0.11 \\
0.62 \pm 0.17 \\
\end{array}$ & $\begin{array}{l}0.56 \\
0.64 \\
\end{array}$ & $\begin{array}{c}0.009-1.04 \\
0.03-1.16 \\
\end{array}$ & 1.49 & $\begin{array}{c}0.14 \\
\mathrm{NS}\end{array}$ \\
\hline
\end{tabular}

SD: Standard deviation MW: Mann Whitney test NS: Non significant $(P>0.05)$ 


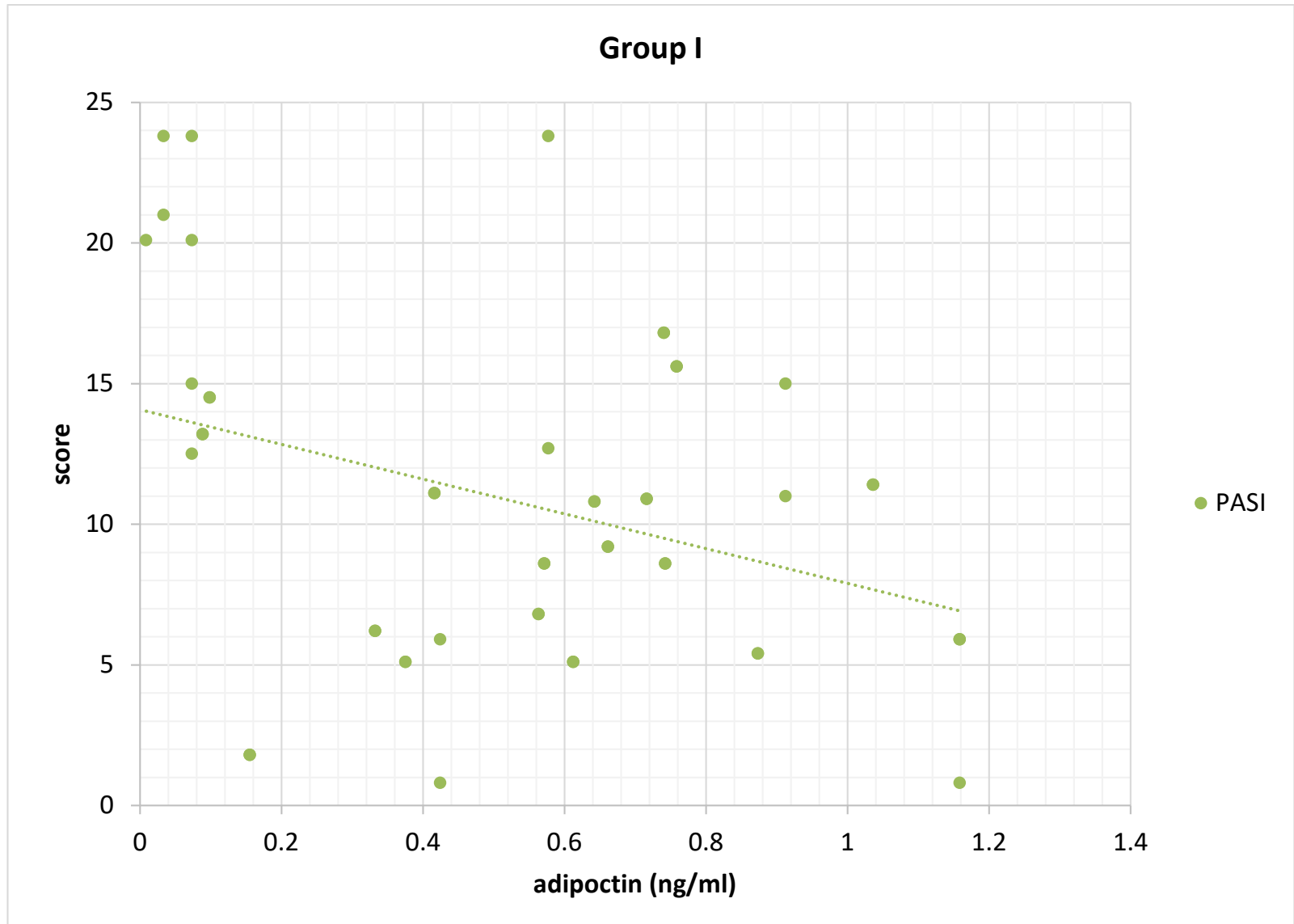

Figure (1): Correlation between serum adiponectin level \& PASI among Group I.

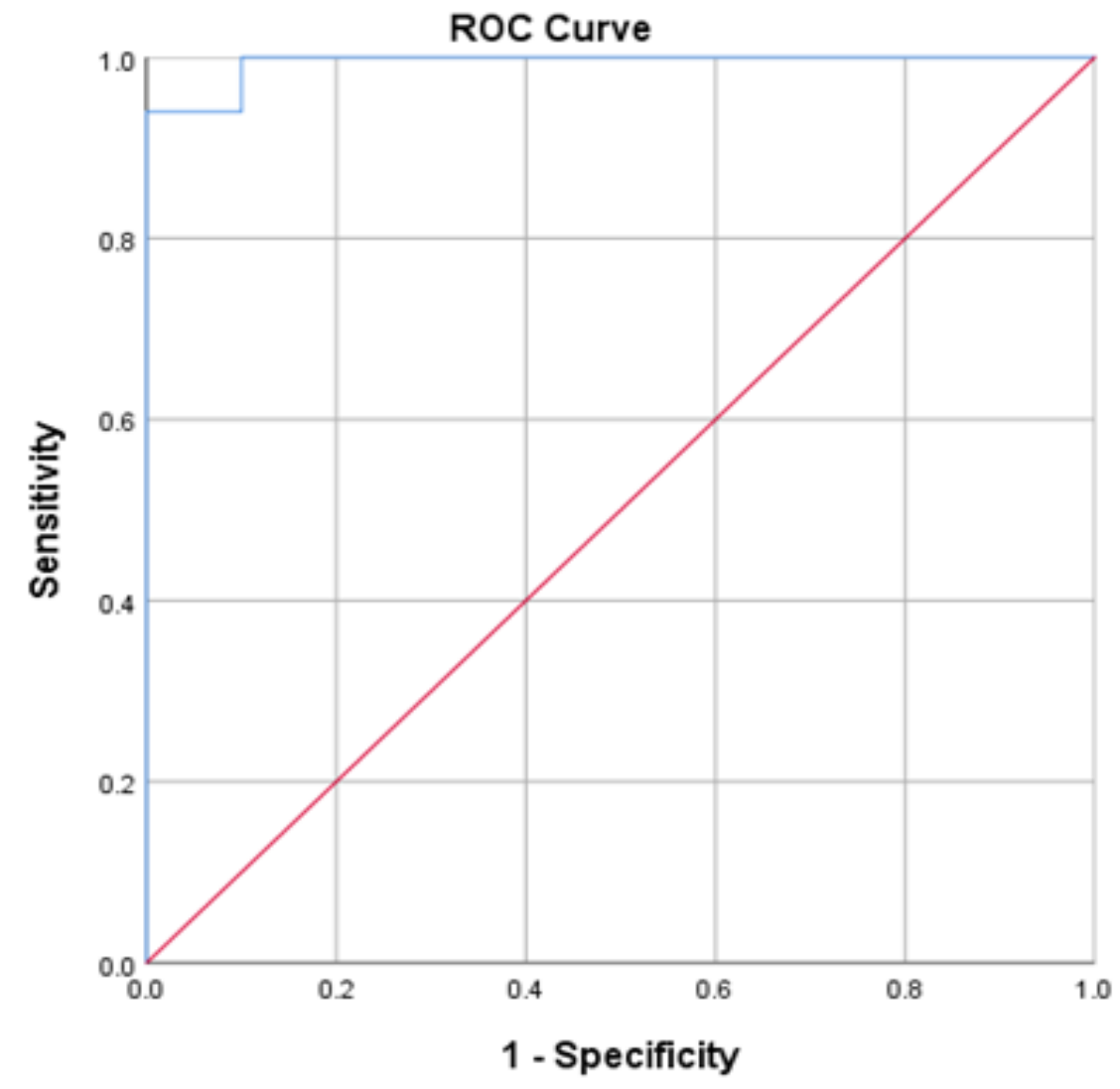

Figure (2): ROC curve for Validity of adiponectin in diagnosis of psoriasis among the studied groups. 


\section{DISCUSSION}

Adiponectin is one of the most widely studied adipokines which is produced and secreted predominantly by fat cells in white adipose tissue ${ }^{(\mathbf{1 6})}$.

High adiponectin plasma levels are associated with decrease the risk to develop type 2 diabetes and metabolic syndrome (MS). Also, it inhibits inflammation, and decreases the production of TNF- $\alpha$ and IL- 6 while increases the production of antiinflammatory mediators like IL-10 and IL-1RA in monocytic cells ${ }^{(\mathbf{1 7})}$.

In the present study, we sought to identify if there is any relation between the serum level of adiponectin and severity of psoriasis. This study revealed that psoriasis was more prevalent in male $(60 \%$ males and $40 \%$ females), that is similar to the results obtained by Bai et al. ${ }^{(18)}$. As regard obesity, the percentage of obese and non-obese persons in psoriasis group was $36 \%$ and $64 \%$; in control group was $42 \%$ and $58 \%$, with no statistically significant difference between the two groups. These results are consistent with those reported by $\mathrm{Oh}$ et al. ${ }^{\left({ }^{19}\right)}$. In contrast to our findings, the study of Murray et al. ${ }^{(20)}$ confirmed the positive association between BMI and psoriasis severity. This difference may be related to large number of patients included in their study. Also, this study was done in a different demography (South-western). Concerning the duration, it is evident from the achieved results that the duration of psoriasis among the studied psoriasis group ranged from 1 to 20 years which is different from the study of Baran $\boldsymbol{e t}$ al. ${ }^{(21)}$ which reported that disease duration varied from 7 months to 55 years.

Regarding the family history in our study, only $4 \%$ of patients had +ve family history of psoriasis, while Oh, et al. who studied Korean patients found that 29.2 $\%$ of patients showed positive family history of psoriasis ${ }^{(19)}$. On detecting psoriatic patients suffering from other diseases, as hypertension and diabetes (Metabolic syndrome), our results reported that 38\% of the cases have Metabolic syndrome. Bavoso et al. (22) study found that DM was detected in $19.5 \%$ of the cases and in $2.4 \%$ of the controls which was dissimilar to our findings. The results revealed that the control group had significantly higher level of adiponectin than patients with psoriasis. This finding was in agreement with those reported by $\mathrm{Oh}$ et al. ${ }^{(19)}$ who stated that serum adiponectin levels significantly lower in psoriasis patients than the controls.

Also, the results of Campanati et al. (21) and Baran et al. ${ }^{(23)}$ were close to our findings, who observed that levels of adiponectin in psoriatic patients were significantly lower than controls. Our outcomes were closely similar to that reported by Acar $\boldsymbol{e t ~ a l . ~}{ }^{\text {(24), }}$ who showed that mean adiponectin level in patients with psoriasis was $25.7(8.9-101.8) \mathrm{ng} / \mathrm{ml}$ compared to $37.5(8.7-222.9) \mathrm{ng} / \mathrm{ml}$ in controls. In contrast to our results, the Chinese study of Zhu et al. ${ }^{(25)}$, informed that adiponectin levels were not significantly different in patients with psoriasis compared with controls.

This difference may relate to smaller number and older age of patients included in our study compared to the other study. In the current study there was a negative significant correlation between adiponectin and PASI score. Such findings were similar to what had been reported by Oh $\boldsymbol{e t ~ a l . ~}{ }^{(19)}$, who found that there was a negative correlation between plasma adiponectin and PASI score. In contrast to the present finding Baran et al. (21), who demonstrated a significant positive correlation between the adiponectin level and PASI. Furthermore, increase adiponectin concentration was noted only in patients with PASI score above 20 (severe cases). This difference may be related to larger number of severe cases conducted in their study. Furthermore Acar et al. ${ }^{(23)}$, results showed no significant correlations between PASI levels and serum HMW adiponectin levels.

This difference may be related to smaller concentration of HMW adiponectin measured in their study than total adiponectin in our study. Our finding showed that there was no statistically significant relationship between sex, obesity, family history, metabolic syndromes and adiponectin level among psoriasis group. These findings were similar to finding detected by Oh et al. ${ }^{\left({ }^{19)}\right.}$ and Bavoso et al. ${ }^{(22)}$. In reverse to our results, Baran et al. ${ }^{(21)}$, demonstrated that Adiponectin was negatively correlated to BMI. Sensitivity of Adiponectin in diagnosis of psoriasis was $94 \%$, specificity was $90 \%$ and accuracy was $92 \%$ so adiponectin measurement in serum of patients with psoriasis provides a tool for monitoring disease activity and a marker of disease severity.

\section{CONCLUSION}

It could be concluded that adiponectin measurement in serum of patients with psoriasis correlated with the clinical state and it is highly specific, sensitive and accurate in diagnosis of psoriasis. Also, adiponectin might be a new biomarker for prediction and evaluation of psoriasis severity as it is closely connected with the inflammatory states in psoriasis. Adiponectin might be a useful marker for the assessment of psoriasis treatment and clinical follow-up of those patients.

Declaration of interest: The authors report no conflicts of interest.

Funding information: None declared.

\section{REFERENCES}

1. Parisi R, Symmons D, Griffiths C et al. (2013): Global epidemiology of psoriasis: a systematic review of incidence and prevalence. Journal of Investigative Dermatology, 133(2): 377-385. 
2. Chapman B, Moynihan J (2009): The brain-skin connection: role of psychosocial factors and neuropeptides in psoriasis. Expert Rev Clin Immunol., 5(6):623-627.

3. Toussirot E, Aubin F, Dumoulin G (2014): Relationships between adipose tissue and psoriasis, with or without arthritis. Front Immunol., 5:368-73.

4. Fisman E, Tenenbaum A (2014): Adiponectin: a manifold therapeutic target for metabolic syndrome, diabetes, and coronary disease?. Cardiovascular Diabetology, 13(1): 1-10.

5. Fruebis J, Tsao T, Javorschi $\mathrm{S}$ et al. (2001): Proteolytic cleavage product of $30-\mathrm{kDa}$ adipocyte complement-related protein increases fatty acid oxidation in muscle and causes weight loss in mice. Proceedings of the National Academy of Sciences, 98(4): 2005-2010.

6. Coppola A, Marfella R, Coppola L et al. (2009): Effect of weight loss on coronary circulation and adiponectin levels in obese women. International Journal of Cardiology, 134(3): 414-416.

7. Sulistyoningrum D, Gasevic D, Lear S et al. (2013): Total and high molecular weight adiponectin and ethnicspecific differences in adiposity and insulin resistance: a cross-sectional study. Cardiovascular Diabetology, 12(1): 1-8.

8. Eder L, Jayakar J, Pollock R et al. (2013): Serum adipokines in patients with psoriatic arthritis and psoriasis alone and their correlation with disease activity. Ann Rheum Dis., 72(12):1956-1961.

9. Özdemir M, Yüksel M, Gökbel H et al. (2012): Serum leptin, adiponectin, resistin and ghrelin levels in psoriatic patients treated with cyclosporin. The Journal of Dermatolosgy, 39(5): 443-448..

10. Shibata S, Saeki H, Tada Y et al. (2009): Serum high molecular weight adiponectin levels are decreased in psoriasis patients. Journal of Dermatological Science, 55(1): 62-63.

11. Naldi L, Chatenoud L, Linder D et al. (2005): Cigarette smoking, body mass index, and stressful life events as risk factors for psoriasis: results from an Italian case-control study. Journal of Investigative Dermatology, 125(1): 61-67.

12. Langley R, Ellis C (2004): Evaluating psoriasis with psoriasis area and severity index, psoriasis global assessment, and lattice system physician's global assessment. Journal of the American Academy of Dermatology, 51(4): 563-569.
13. Berth-Jones $\mathrm{J}$, Grotozinger $\mathrm{K}$, Rainville $\mathrm{C}$ et al. (2006): A study examining inter- and intrarater reliability of three scales for measuring severity of psoriasis: Psoriasis Area and Severity Index, Physician's Global Assessment and Lattice System Physician's. Global Assessment, 155(4):707-13.

14. Yildirım Y, Polat M, Serin E et al. (2012): Serum TNF-a, IL-6 and resistin levels in chronic plaque psoriasis. Türkderm.., 46:138-42.

15. Kadowaki T, Yamauchi T (2005): Adiponectin and adiponectin receptors. Endocr Rev., 26: 439-451.

16. Heiberger R, Neuwirth E. (2009): One-way anova. In R through excel. Springer New York, NY., Pp. 165-191.

17. Straub L, Scherer $P$ (2019): Metabolic messengers: adiponectin. Nature Metabolism, 1(3): 334-339.

18. Bai F, Zheng W, Dong Y et al. (2018): Serum levels of adipokines and cytokines in psoriasis patients: a systematic review and meta-analysis. Oncotarget, 9(1): 1266-73.

19. Oh Y, Lim H, Choi J et al. (2014): Serum leptin and adiponectin levels in Korean patients with psoriasis. Journal of Korean Medical Science, 29(5): 729-735.

20. Murray M, Bergstresser $P$, Adams-Huet $B$ et al. (2009): Relationship of psoriasis severity to obesity using same-gender siblings as controls for obesity. Clin Exp Dermatol., 34:140-4.

21. Baran A, Flisiak I, Jaroszewicz J et al. (2015): Effect of psoriasis activity on serum adiponectin and leptin levels. Advances in Dermatology and Allergology/Postępy Dermatologii i Alergologii, 32(2): 101-105.

22. Bavoso N, Pinto J, Soares M et al. (2019): Psoriasis in obesity: comparison of serum levels of leptin and adiponectin in obese subjects-cases and controls. Anais brasileiros de dermatologia, 94(2): 192-197.

23. Campanati A, Ganzetti G, Giuliodori K et al. (2015): Serum levels of adipocytokines in psoriasis patients receiving tumor necrosis factor- $\alpha$ inhibitors: results of a retrospective analysis. International Journal of Dermatology, 54(7): 839-845.

24. Acar E, İlter N, Elbeg Ş (2019): Association of leptin, resistin, and high-molecular-weight adiponectin levels with psoriasis area and severity index scores, obesity, and insulin resistance in psoriasis patients. Dermatologica Sinica, 37(1): 33.

25. Zhu K, Shi G, Zhang $C$ et al. (2013): Adiponectin levels in patients with psoriasis: A meta-analysis. The Journal of Dermatology, 40(6): 438-442. 